\title{
Efficacy and safety of Syferol-IHP for the treatment of peptic ulcer disease: a pilot, double-blind randomized trial
}

This article was published in the following Dove Medical Press journal:

Clinical and Experimental Gastroenterology

\section{George Uchenna Eleje, ${ }^{1,2}$ Henrietta Aritetsoma Ogbunugafor, ${ }^{1,3}$ Chiemelu Dickson Emegoakor, ${ }^{1,4}$ Ebere Innocent Okoye, ${ }^{1,5}$ Ogochukwu Ifeanyi Ezejiofor, ${ }^{6}$ Shirley Nneka Chukwurah, ${ }^{7}$ Joseph Ifeanyichukwu Ikechebelu, ${ }^{1,2}$ Godwin W Nchinda, ${ }^{8}$ Chidozie Godwin Ugochukwu, ${ }^{3}$ Lucy ljeoma Nnaji-lhedinmah, ${ }^{9}$ Festus Basden C Okoye, ${ }^{1,10}$ Frank Uchenna Eneh, ${ }^{3}$ Michael Emeka Onwukamuche," Charles Okechukwu Esimone ${ }^{1,12}$}

'Biomedicine Research Group, Nnamdi Azikiwe University, Awka, Nigeria; ${ }^{2}$ Effective Care Research Unit, Faculty of Medicine, College of Health Sciences, Nnamdi Azikiwe University, Awka, Nigeria; ${ }^{3}$ Department of Applied Biochemistry, Nnamdi Azikiwe University, Awka, Nigeria; ${ }^{4}$ Department of General Surgery, Nnamdi Azikiwe University, Awka, Nigeria; ${ }^{5}$ Department of Pharmaceutics and Pharmaceutical Technology, Nnamdi Azikiwe University, Awka, Nigeria; ${ }^{6}$ Department of Medicine, Nnamdi Azikiwe University, Awka, Nigeria; ${ }^{7}$ Gastroenterology Unit, Department of Medicine, Nnamdi Azikiwe University Teaching Hospital, Nnewi, Nigeria; ${ }^{8}$ Laboratory of Vaccinology/Biobanking, CIRCB BP 3077, Messa Yaounde, Cameroon; 'Department of Chemical Pathology, Nnamdi Azikiwe University Teaching Hospital, Nnewi, Nigeria; ${ }^{10}$ Department of Pharmaceutical and Medicinal Chemistry, Nnamdi Azikiwe University, Awka, Nigeria; "Department of Histopathology, Faculty of Medicine, Nnamdi Azikiwe University, Awka Nigeria; ${ }^{2}$ Department of Pharmaceutical Microbiology and Biotechnology, Nnamdi Azikiwe University, Awka, Nigeria

Correspondence: George Uchenna Eleje Biomedicine Research Group, Nnamdi Azikiwe University, Awka, PMB 5025, Awka, Along Enugu-Onitsha Expressway, Ifite Awka NG 4201 I0, Anambra State, Nigeria

Tel +2348068II 7444

Email gu.eleje@unizik.edu.ng
Background: To our knowledge, there is no prior randomized study on the utility of SyferolIHP (blend of virgin coconut oil and Ocimum sanctum oil) when coadministered with a triple therapy schedule.

Aim: This study determined the efficacy and safety of Syferol-IHP as adjunct to conventional triple therapy for the treatment of peptic ulcer disease (PUD).

Methods: A pilot double-blind randomized trial was conducted in patients with confirmed diagnosis (endoscopy-guided biopsy) of PUD. Eligible patients were randomized to Pylorest (a three-in-one tablet containing rabeprazole $20 \mathrm{mg}$, amoxicillin $1 \mathrm{~g}$, and clarithromycin $500 \mathrm{mg}$ ) and Syferol-IHP for 2 weeks, followed by rabeprazole and Syferol-IHP for 2 weeks or Pylorest and placebo for 2 weeks, followed by rabeprazole and placebo for 2 weeks. Repeat endoscopy-guided biopsy and histology were done 4 weeks posttherapy. Primary outcome measures were the healing of ulcer and eradication of Helicobacter pylori. Secondary outcome measures were the disappearance of epigastric pain, gastritis, and duodenitis. Analysis was by intention-to-treat.

Results: Of the 63 patients enrolled, 60 patients had complete evaluation, with 37 patients receiving Pylorest and Syferol-IHP and 23 patients receiving Pylorest and Placebo. Healing of the PUD in favor of Pylorest and Syferol-IHP was significantly higher for gastric ulcer ( $R R=0.000,95 \%$ $\mathrm{CI}=$ undefined, $P=0.048)$ but not for duodenal ulcer $(\mathrm{RR}=0.400,95 \% \mathrm{CI}=0.07-2.37, P=0.241) . H$. pylori eradication was $100 \%$ with Syferol-IHP vs $50 \%$ with placebo $(P=0.066)$. Epigastric pain (reduction to $16.2 \%$ vs $43.5 \% ; P=0.021$ ), gastritis (reduction to $13.5 \%$ vs $39.1 \% ; P=0.024$ ), and duodenitis (reduction to $0 \%$ vs $8.7 \% ; P=0.327$ ) were observed in the Syferol-IHP and Pylorest vs placebo and Pylorest groups, respectively. Adverse events $(\mathrm{RR}=0.971,95 \% \mathrm{CI}=0.46-2.04$, $P=0.937)$ and laboratory parameters were not significantly different pre- and posttherapies ( $P>0.05$, for both groups).

Conclusion: Although both treatment arms were equally safe, co-administration of Syferol-IHP and triple therapy is more efficacious than triple therapy alone for treating PUD. Pan African Clinical trial registry identifier number is PACTR201606001665364.

Keywords: gastritis, duodenitis, virgin coconut oil, Ocimum sanctum oil, triple therapy, Pylorest, gastric ulcer

\section{Background}

Peptic ulcer disease (PUD) is increasingly recognized as a major gastrointestinal disease affecting the stomach and duodenum. It arises from the deleterious effects of certain ulcerogenic agents such as the bacterium Helicobacter pylori, NSAIDs, and alcohol. ${ }^{1,2}$ These agents may cause an increase in the levels of acid production or disrupt the integrity of the mucosal walls of the stomach or intestines, thereby exposing them to 
the acid attack. ${ }^{3}$ Recent data have shown that PUD remains a relatively common global condition, with yearly prevalence ranging from $0.12 \%$ to $1.5 \%$ for physician-diagnosed PUD and from $0.10 \%$ to $0.19 \%$ for PUD diagnosed during hospitalization. ${ }^{4}$

Although the process of how $H$. pylori induces the development of different types of lesions in the gastroduodenal mucosa is not completely understood, in recent years, a number of contributory mechanisms have been recognized to initiate and propagate the disease. ${ }^{1,3}$ An imbalance between mucosal defensive mechanisms and aggressive factors, including a gastric acid hypersecretory status, is believed to exist. ${ }^{1}$ A number of gastric secretion studies were done in the pre- $H$. pylori era, and hitherto, it is known that most of the alterations were secondary to the effect of $H$. pylori infection. ${ }^{1}$

To date, the management of PUD has become more challenging than ever because of the menace of increasing global antimicrobial resistance. ${ }^{1,5}$ In addition, PUD not associated with $H$. pylori infection or the use of NSAIDs is now also imposing substantial diagnostic and therapeutic challenges. ${ }^{1}$ Conventionally available and accepted therapies for the management of PUD are associated with a vast array of noxious side effects, and the cost of treatment with these agents could be enormous. ${ }^{2,3}$ One recent meta-analysis on PUD therapy revealed that standard triple therapy consisting of proton pump inhibitors, such as amoxicillin and clarithromycin, were suboptimal. ${ }^{6}$ Also, in a recent Cochrane review aimed at assessing the proportion of peptic ulcers healed and the proportion that remained free from relapse with eradication therapy against placebo or other pharmacological therapies in PUD, it was concluded that there is no evidence at present that $H$. pylori eradication therapy is an effective treatment in people with PUD compared to ulcer healing drug alone. ${ }^{7}$ PUD can recur and becomes a chronic problem or can lead to a number of serious complications including gut perforation and upper gastrointestinal bleeding. ${ }^{8}$ Therefore, there is need for more alternative or adjunctive therapy for PUD.

Syferol-IHP (produced by Bioresource Development Group, Abuja, Nigeria) is a special blend of virgin coconut oil (VCO) and cold-pressed Ocimum sanctum oil, which reportedly have been shown to be very effective in the treatment of PUD. ${ }^{9-12}$ VCO (Cocos nucifera L. Arecaceae) works by exhibiting antibacterial property on $H$. pylori, thereby helping in the amelioration of the symptoms of PUD. ${ }^{13}$ Studies have shown that $O$. sanctum oil, which is basil oil, has antibacterial and antiulcerogenic activities. ${ }^{13-15}$ Therefore, Syferol-IHP is a combination of natural product therapy. ${ }^{16,17}$
The potential antibacterial property of Syferol-IHP is made possible based on the fact that the coconut oil is made up of saturated fatty acids of the medium chain variety mostly lauric acid. ${ }^{13}$ Lauric acid has been demonstrated to be bactericidal in its activity without exerting undue adverse side effect as it is easily metabolized by humans. Also, the medium chain fatty acids of VCO are easily digestible. ${ }^{13}$

Anecdotal reports have shown that there is strong improvement in PUD symptoms following the ingestion of triple therapy in combination with Syferol-IHP. This lends support to the hypothesis that triple therapy for PUD in combination with Syferol-IHP might be needed to achieve maximum and optimum clinical benefits. To our knowledge, this is the first randomized study reporting the efficacy and safety of this combined Syferol-IHP and triple therapy schedule. We therefore designed this pilot randomized double-blind trial to compare the efficacy and safety of Syferol-IHP on adult patients with PUD when used as adjuncts with conventional triple therapy.

\section{Methods \\ Study setting}

The study was carried out at the Nnamdi Azikiwe University Teaching Hospital (NAUTH), Nnewi, and Chukwuemeka Odumegwu Ojukwu University Teaching Hospital (COOUTH), Amaku, Awka, being government-owned hospitals in the South-East of Nigeria. They are public tertiary institutions. All the endoscopic procedures were done by CDE at Eldorado Multi-Specialist Hospital, Awka, Nigeria, a hospital that is accredited for the management of adults with PUD.

\section{Study design}

This was a double-blind randomized trial, parallel group in a randomization ratio of $1: 1$.

\section{Study population}

The participants comprised both male and female adult patients with the endoscopy diagnosis of PUD and who had given their written informed consent before recruitment. The patients were recruited at the outpatient clinics or referred for the treatment of their dyspeptic symptoms.

\section{Inclusion criteria}

Both male and female individuals aged between 18 and 60 years with the confirmed diagnosis of PUD and with normal liver and renal function markers and hematological profiles were included. 


\section{Exclusion criteria}

Pregnant women and those with complications arising from PUD such as bleeding and perforation were excluded.

\section{Randomization and allocation sequence}

From January 2017 until August 2017, 77 patients at two hospitals were screened for eligibility. The patients eligible for the study were randomized into two groups using a simple (nonblock) randomization table created by a computer software program by a person not involved in the study and available at www.researchrandomizer.org. Allocation sequences and codes were concealed from the person allocating the participants to the intervention arms using numbered containers containing drugs.

\section{Blinding of participants, personnel, and outcome assessors}

Syferol-IHP and the placebo consisting of liquid preparations (containing mixture of carboxymethyl cellulose, tartrazine yellow, and orange- and banana-flavored purified water) were packed in identical opaque bottles. Participants could not distinguish from one preparation (Syferol-IHP and conventional triple therapy) to the other (conventional triple therapy and placebo for Syferol-IHP). Both personnel and outcome assessors were also blinded.

\section{Study procedure/drug administration}

Patients with a clinical diagnosis of PUD presenting in Medical Outpatient Clinic of the hospitals for symptoms such as abdominal or epigastric pain, abdominal discomfort, vomiting, and other symptoms relating to PUD were screened consecutively. All patients also underwent routine medical examination including pulse rate, body weight, blood pressure determination, and abdominal examination to ascertain the presence and severity of abdominal or epigastric tenderness. All consenting patients were diagnosed to have either PUD or not after undergoing upper gastrointestinal tract endoscopy.

Eligible patients were sequentially allocated using an opaque sealed envelope to receive either Syferol-IHP and conventional triple therapy or the placebo for Syferol-IHP and conventional triple therapy in a double-blinded pattern. Therapies were given for 4 weeks.

\section{Intervention therapy}

Standard doses of $20 \mathrm{~mL}$ of Syferol-IHP were administered in conjunction with Pylorest (Saga Laboratories, Ahmedabad, India) tablets (a three-in-one tablet containing rabeprazole
$20 \mathrm{mg}$, amoxicillin $1 \mathrm{~g}$, and clarithromycin $500 \mathrm{mg}$ ) two times a day (breakfast and dinner) for 2 weeks and then followed by Rabefast (Pulse Pharmaceuticals Pvt Ltd, Uttarakhand, India) tablet containing $20 \mathrm{mg}$ of rabeprazole, administered twice daily for another 2 weeks.

\section{Control therapy}

Standard doses of $20 \mathrm{~mL}$ of placebo for Syferol-IHP were administered in conjunction with Pylorest tablets (a threein-one tablet containing rabeprazole $20 \mathrm{mg}$, amoxicillin $1 \mathrm{~g}$, and clarithromycin $500 \mathrm{mg}$ ) two times a day (breakfast and dinner) for 2 weeks and followed by $20 \mathrm{mg}$ of rabeprazole administered twice daily for another 2 weeks.

\section{Follow-up}

During each follow-up weekly visit, patients were encouraged and/or reminded to avoid smoking, aspirin, and other NSAIDs. Patients were contacted through phone on daily basis to assess the level of compliance. The patients were also encouraged to record any side effects or adverse events in a paper that was reviewed at each follow-up visit, and they were explicitly asked about such events during each interview. The drug compliance was checked before the follow-up test. Any patient found to be developing complications such as perforation and bleeding were discontinued from the study and were given appropriate treatment. Repeat upper gastrointestinal endoscopy was done 4 weeks posttreatment in all the participants to confirm the success of treatment (ulcer healing) and the absence of adverse effects. All the pre- and post-(repeat) upper gastrointestinal endoscopies were carried out by $\mathrm{CDE}$.

\section{Outcome measures}

Primary endpoints were the healing of ulcer and the eradication of $H$. pylori. Secondary endpoints were the disappearance of epigastric pain, gastritis, and duodenitis and the presence of adverse events. Other secondary outcome measures included renal function tests (serum electrolyte, urea, and creatinine), liver function tests, and lipid profile parameters and were repeated 4 weeks posttreatment.

\section{Statistical analysis}

No formal sample size calculations were made because of the pilot nature of the study. Interim analysis was planned. Data were analyzed using the statistical analysis, which was performed by SPSS Version 21 (IBM Corporation, Armonk, NY, USA). The data were expressed as the number (\%), mean (SD), and mean $(95 \% \mathrm{CI})$ as appropriate. Categorical variables were compared using the Chi-squared test and 
Fisher's exact test, as necessary. Independent $t$-test was used to compare the mean of continuous variables between treatment groups. The intention-to-treat efficacy analyses were based on all the patients who received the study medication and had completed the follow-up visit. The number needed to treat (NNT) analysis (the number of patients who need to be treated for one of them to benefit compared with a control in a clinical trial) was also done. Patients with no observed outcome were considered as treatment failures. A univariate analysis was employed. When possible, subgroup analysis was also planned. A $P$-value of $\leq 0.05$ was considered to be statistically significant.

\section{Ethical consideration}

The study adheres to CONSORT guidelines. The study protocol was approved by the ethics committee of NAUTH, Nnewi, Nigeria (NAUTH/CS/66/VOL.9/93; approval date: November 7, 2016), and the ethics committee of COOUTH, Amaku, Awka, Nigeria (COOUTH/AA/vol.1.016; approval date: August 1, 2016). The study was also registered with the Pan African Clinical trial registry: PACTR201606001665364 at www.pactr.org. The trial was registered on June 1, 2016. The procedures followed were in accordance with the guidelines of the World Medical Association's Declaration of Helsinki (1964) and its later amendments.

\section{Results}

\section{Baseline characteristics of study participants}

The characteristics of all randomized patients at baseline are shown in Table 1. The groups were balanced with respect to baseline characteristics (age, gender, H. pylori-positive lesions, and full blood count parameters). Seventy-seven participants at two hospitals were screened for eligibility. Of these patients, 63 patients were included in the study and 14 patients did not fulfill the criteria for randomization and were excluded. The reasons for exclusion were not agreeing to participate in the study $(n=4)$ and no positive findings at endoscopy $(n=7)$ and bleeding ulcer $(n=3)$. All patients included in the study were adults and were nontreatment naive.

Of the 63 patients, 39 patients received Syferol-IHP with conventional triple therapy and 24 patients received placebo and conventional triple therapy. Of the 60 patients who completed their follow-up visits, 43 patients had endoscopyguided biopsy of the lesion. Six (16.2\%) of the 37 patients in the Syferol group and four (17.4\%) of the placebo group were $H$. pylori positive, whereas $12(32.4 \%)$ and $5(21.7 \%)$ had unknown $H$. pylori status, as shown in Table 2.

Although none of the patients withdrew consent after randomization, one was lost to follow-up in the triple therapy-Syferol-IHP group and one was lost to follow-up in the triple therapy-placebo group. A total of 37 patients from the triple therapy-Syferol-IHP group and 23 in the triple therapy-placebo group completed the study with follow-up data of 4 weeks after enrollment (Figure 1). The study was stopped after completing the follow-up of 60 participants due to costs.

\section{Change in ulcer frequency as primary end point}

The effects on healing of the ulcer in favor of Syferol-IHP were statistically significantly different for gastric ulcer (RR $=0.000,95 \% \mathrm{CI}=$ undefined, $\mathrm{NNT}=1.7, P=0.048$ ) but not for duodenal ulcer $(\mathrm{RR}=0.400,95 \% \mathrm{CI}=0.07-2.37$, NNT=3.0; $P=0.241)$.

Table I Baseline demographic and clinical characteristics of the participants

\begin{tabular}{|c|c|c|c|c|}
\hline Parameter & $\begin{array}{l}\text { CTT and Syferol-IHP }(\mathbf{N}=37) \\
\text { Frequency }(\%)\end{array}$ & $\begin{array}{l}\text { CTT and placebo }(\mathrm{N}=23) \\
\text { Frequency }(\%)\end{array}$ & $\operatorname{RR}(95 \% \mathrm{Cl})$ & $P$-value \\
\hline Age (years) & $45.7 \pm 3.9$ & $44.8 \pm 4.1$ & £ 0.853 & 0.3976 \\
\hline \multicolumn{5}{|l|}{ Gender } \\
\hline Male & $16(43.2)$ & II (47.8) & $0.93(0.62-1.40)$ & 0.731 \\
\hline Female & $21(56.8)$ & $12(52.2)$ & & \\
\hline \multicolumn{5}{|c|}{ Duration of symptoms (months) } \\
\hline$<12$ & $3(8.1)$ & $\mathrm{I}(4.3)$ & & \\
\hline$\geq 12$ & 34 (91.9) & $22(95.7)$ & $0.95(0.84-1.09)$ & 0.961 \\
\hline \multicolumn{5}{|l|}{ Previous PUD treatments } \\
\hline Treatment naive & $0(0.0)$ & $0(0.0)$ & & \\
\hline Nontreatment naive & $37(100.0)$ & $23(100.0)$ & $U$ & 0.214 \\
\hline
\end{tabular}

Notes: Values are expressed as number (\%) of patients. $U$, infinity.

Abbreviations: CTT, conventional triple therapy; PUD, peptic ulcer disease. 
Table 2 Mean values or frequencies and differences in improvement with overall $P$-values after treatment (repeated measures analysis)

\begin{tabular}{|c|c|c|c|c|}
\hline Parameter & $\begin{array}{l}\text { CTT and Syferol-IHP }(\mathrm{N}=37) \\
\text { Frequency }(\%)\end{array}$ & $\begin{array}{l}\text { CTT and placebo }(\mathrm{N}=23) \\
\text { Frequency }(\%)\end{array}$ & $\operatorname{RR}(95 \% \mathrm{Cl})$ & $P$-value \\
\hline \multicolumn{5}{|l|}{ HB concentration $(\mathrm{g} / \mathrm{dL})$} \\
\hline Baseline & $11.9 \pm 2.1$ & $12.9 \pm 2.8$ & & \\
\hline After treatment & $12.2 \pm 3.4$ & $12.3 \pm 3.1$ & $t-0.1145$ & 0.909 \\
\hline \multicolumn{5}{|l|}{ WBC count $(\mathrm{mL})$} \\
\hline Baseline & $4170 \pm 423.0$ & $4355 \pm 449.0$ & & \\
\hline After treatment & $4|25 \pm 39| .3$ & $4320 \pm 407.7$ & $t-0.8998$ & 0.372 \\
\hline \multicolumn{5}{|l|}{ Epigastric pain } \\
\hline Baseline & $37(100.0)$ & $23(100.0)$ & & \\
\hline After treatment & $6(16.2)$ & $10(43.5)$ & $0.532(0.27-1.03)$ & $0.02 I^{*}$ \\
\hline \multicolumn{5}{|l|}{ Endoscopic findings } \\
\hline $\begin{array}{l}\text { Gastritis } \\
\text { Baseline } \\
\text { After treatment }\end{array}$ & $\begin{array}{l}33(89.2) \\
5(13.5)\end{array}$ & $\begin{array}{l}21(91.3) \\
9(39.1)\end{array}$ & $0.510(0.25-1.06)$ & $0.024 *$ \\
\hline $\begin{array}{l}\text { Duodenitis } \\
\text { Baseline } \\
\text { After treatment } \\
\end{array}$ & $\begin{array}{l}2(5.4) \\
0(0.0)\end{array}$ & $\begin{array}{l}5(2 \mathrm{I} .7) \\
2 \text { (8.7) } \\
\end{array}$ & $0.000(U)$ & 0.327 \\
\hline $\begin{array}{l}\text { Gastric ulcer } \\
\text { Baseline } \\
\text { After treatment }\end{array}$ & $\begin{array}{l}9(24.3) \\
0(0.0)\end{array}$ & $\begin{array}{l}3(13.0) \\
2(8.7)\end{array}$ & $0.000(U)$ & $0.048 *$ \\
\hline $\begin{array}{l}\text { Duodenal ulcer } \\
\text { Baseline } \\
\text { After treatment } \\
\end{array}$ & $\begin{array}{l}6(16.2) \\
\mathrm{I}(2.7)\end{array}$ & $\begin{array}{l}6(26.1) \\
3(13.0) \\
\end{array}$ & $0.400(0.07-2.37)$ & $0.24 I$ \\
\hline $\begin{array}{l}\text { Histology } \\
\qquad \begin{array}{l}\text { H. pylori positive } \\
\text { Baseline } \\
\text { After treatment } \\
\text { Unknown }{ }^{\mathrm{a}} \mathrm{H} \text {. pylori }\end{array}\end{array}$ & $\begin{array}{l}6(16.2) \\
0(0.0) \\
12(32.4) \\
\end{array}$ & $\begin{array}{l}4(17.4) \\
2(8.7) \\
5(21.7) \\
\end{array}$ & $0.00(U)$ & 0.066 \\
\hline $\begin{array}{l}\text { H. pylori negative } \\
\text { Baseline } \\
\text { After treatment } \\
\text { Unknown }{ }^{\mathrm{a}} \mathrm{H} \text {. pylori }\end{array}$ & $\begin{array}{l}19(51.4) \\
25(67.6) \\
12(32.4) \\
\end{array}$ & $\begin{array}{l}14(60.9) \\
16(69.7) \\
5(21.7) \\
\end{array}$ & $1.24(0.68-2.28)$ & 0.483 \\
\hline $\begin{array}{l}\text { Biochemical tests } \\
\text { Urea }(\mathrm{mg} / \mathrm{dL}) \\
\text { Baseline } \\
\text { After treatment }\end{array}$ & $\begin{array}{l}4.5 \pm 2.1 \\
4.8 \pm 3.6 \\
\end{array}$ & $\begin{array}{l}5.4 \pm 8.7 \\
3.9 \pm 1.4 \\
\end{array}$ & $t-1.143$ & 0.258 \\
\hline $\begin{array}{l}\text { Creatinine }(\mathrm{mg} / \mathrm{dL}) \\
\text { Baseline } \\
\text { After treatment }\end{array}$ & $\begin{array}{l}102.5 \pm 25.1 \\
93.2 \pm 29.8\end{array}$ & $\begin{array}{l}94.3 \pm 15.5 \\
92.3 \pm 26.9 \\
\end{array}$ & $t 0.118$ & 0.907 \\
\hline $\begin{array}{l}\text { AST }(\mathrm{U} / \mathrm{L}) \\
\text { Baseline } \\
\text { After treatment }\end{array}$ & $\begin{array}{l}\text { II. } 2 \pm 5.1 \\
9.9 \pm 4.2\end{array}$ & $\begin{array}{l}12.1 \pm 5.1 \\
9.1 \pm 3.0\end{array}$ & $t-0.795$ & 0.430 \\
\hline $\begin{array}{l}\text { ALT }(\mathrm{U} / \mathrm{L}) \\
\text { Baseline } \\
\text { After treatment }\end{array}$ & $\begin{array}{l}10.7 \pm 4.8 \\
9.0 \pm 5.6\end{array}$ & $\begin{array}{l}10.7 \pm 4.8 \\
7.6 \pm 3.8 \\
\end{array}$ & $t-1.056$ & 0.296 \\
\hline $\begin{array}{l}\text { ALP }(\mathrm{U} / \mathrm{L}) \\
\text { Baseline } \\
\text { After treatment }\end{array}$ & $\begin{array}{l}38.4 \pm 14.2 \\
37.8 \pm 13.6\end{array}$ & $\begin{array}{l}43.4 \pm 15.0 \\
34.1 \pm 9.2\end{array}$ & $t-1.150$ & 0.255 \\
\hline $\begin{array}{l}\text { LDL }(\mathrm{mmol} / \mathrm{L}) \\
\text { Baseline } \\
\text { After treatment }\end{array}$ & $\begin{array}{l}3.3 \pm 0.9 \\
3.3 \pm 1.2\end{array}$ & $\begin{array}{l}3.3 \pm 0.9 \\
3.5 \pm 1.1\end{array}$ & $t 0.648$ & 0.520 \\
\hline $\begin{array}{l}\text { HDL }(\mathrm{mmol} / \mathrm{L}) \\
\text { Baseline } \\
\text { After treatment }\end{array}$ & $\begin{array}{l}1.3 \pm 0.2 \\
1.8 \pm 1.1\end{array}$ & $\begin{array}{l}1.3 \pm 0.2 \\
1.7 \pm 0.9\end{array}$ & $t-0.366$ & 0.716 \\
\hline
\end{tabular}

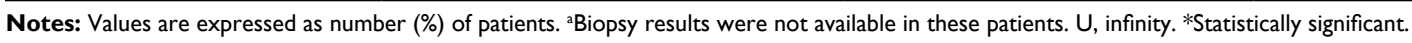

Abbreviations: ALT, alanine transaminase; AST, aspartate transaminase; CTT, conventional triple therapy; HB, hemoglobin; HDL, high-density lipoprotein; $H$. pylori, Helicobacter pylori; LDL, low-density lipoprotein; WBC, white blood cell . 
CONSORT flow diagram

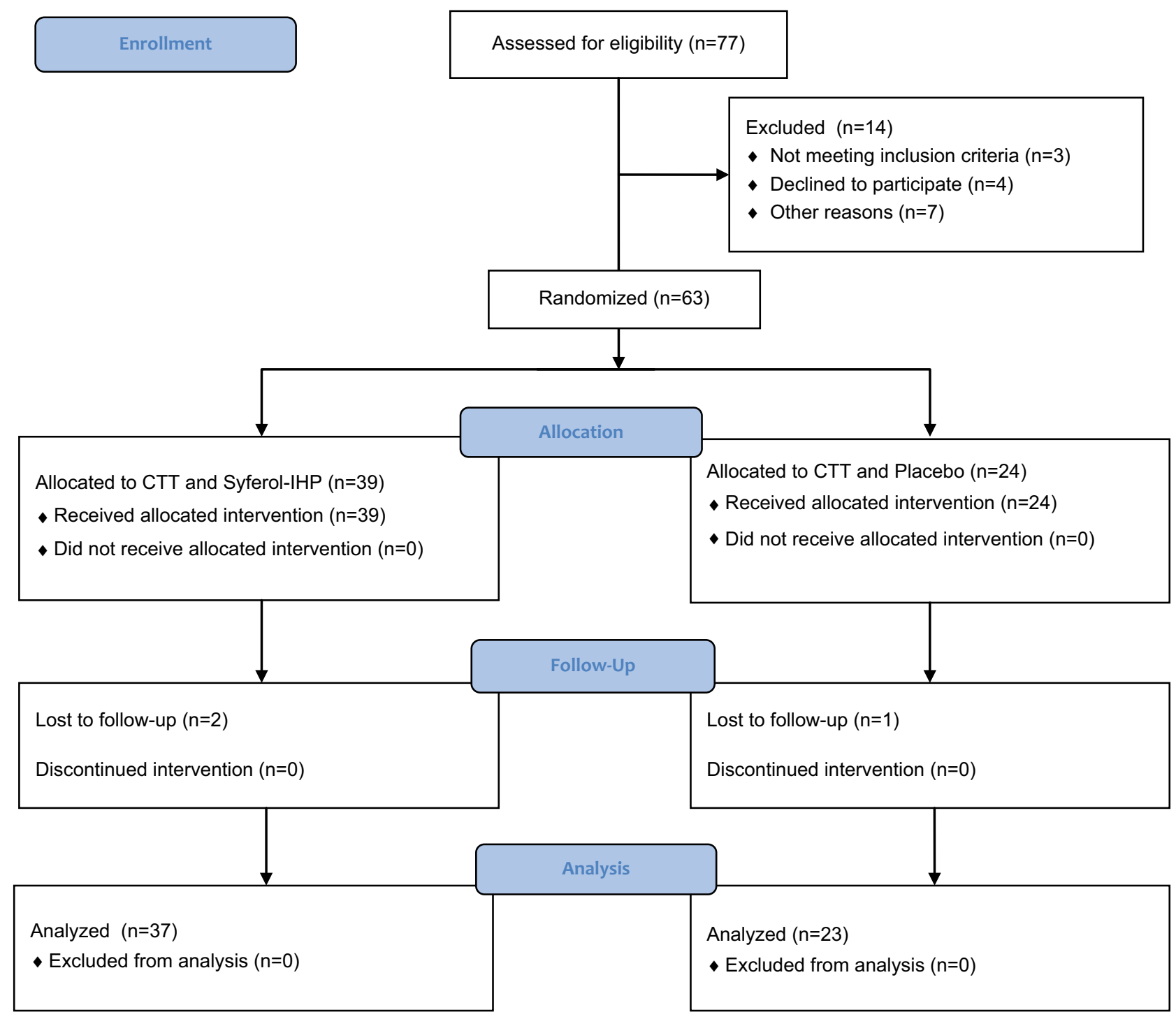

Figure I Flow chart of the patients.

Abbreviation: CTT, conventional triple therapy.

\section{Recovery rate of $H$. pylori-positive lesion} in the patients after 4 weeks follow-up

We also analyzed the recovery rate of $H$. pylori-positive lesion in the patients after at least 4 weeks of follow-up (see Figure 2). After that, $100 \%$ of the Syferol-IHP patients who were H. pylori positive $(\mathrm{n}=6)$ showed full recovery (H. pylori negative) compared to $50.0 \%(\mathrm{n}=4)$ of the placebo group and this difference was not statistically significant $(P=0.066)$. The NNT was 2.3 .

\section{Secondary endpoints of study outcome} Epigastric pain

There was no difference in baseline epigastric pain between the treatment groups, Syferol-IHP $(n=37[100.0 \%])$ vs placebo $(\mathrm{n}=23[100.0 \%])(P=0.2143)$. After 4 weeks' follow-up, the absolute improvement in the epigastric pain was a reduction to $16.2 \%$ in the Syferol-IHP vs $43.5 \%$ in the placebo group, which was statistically significant (NNT $=3.7 ; P=0.021)$.

\section{Gastritis}

There was no difference in baseline gastritis between the treatment groups: 33 of the 37 (89.2\%) patients receiving Syferol-IHP had gastritis, whereas 21 of the $23(91.3 \%)$ receiving placebo had gastritis $(P=0.8410)$ (see Figure 3). After 4 weeks' follow-up, the absolute improvement in the gastritis was a reduction to $13.5 \%$ in the Syferol-IHP group 


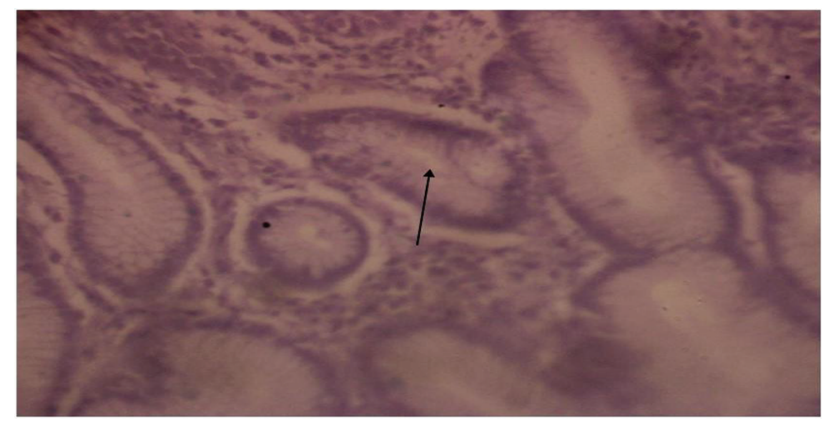

Figure 2 Special stain (Giemsa) $\times 400$ showing Helicobacter pylori organisms (arrow) within the gastric gland.

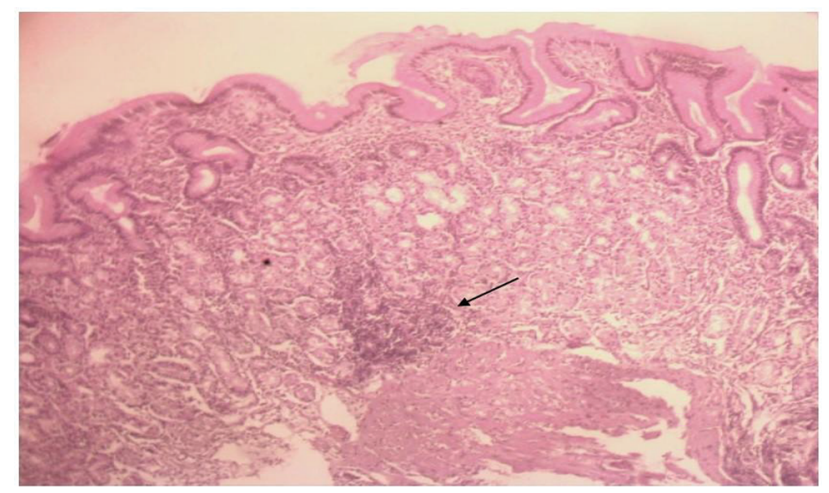

Figure 3 Severe chronic gastritis $\times 100$ magnification.

Note: Lymphocytic infiltrates (arrow) are seen forming follicle (pretreatment result).

vs $39.1 \%$ in the placebo group, which was statistically significant $(\mathrm{RR}=0.510,95 \% \mathrm{CI}=0.25-1.06, \mathrm{NNT}=3.6, P=0.024)$, as shown in Table 2. and illustrated in Figure 4.

\section{Duodenitis}

Duodenitis was also analyzed from diagnosis at endoscopy in all the enrolled patients. There was no difference in duodenitis at baseline between the treatment groups: two of the 37 (5.4\%) patients receiving Syferol-IHP had duodenitis and five of the $23(21.7 \%)$ patients receiving placebo had duodenitis $(P=0.057)$. After 4 weeks' follow-up, the absolute improvement in the duodenitis was a reduction to $0 \%$ in the SyferolIHP vs $8.7 \%$ in the placebo group, which was not statistically significant $(\mathrm{NNT}=4.0 ; P=0.327)$, as shown in Table 2 .

\section{Safety of treatment}

Adverse events (nausea and vomiting and dizziness) were reported in five patients, three patients in the Syferol group and two patients in the placebo group. No patients failed to complete the protocol due to side effects. There was no significant difference between the two groups in adverse

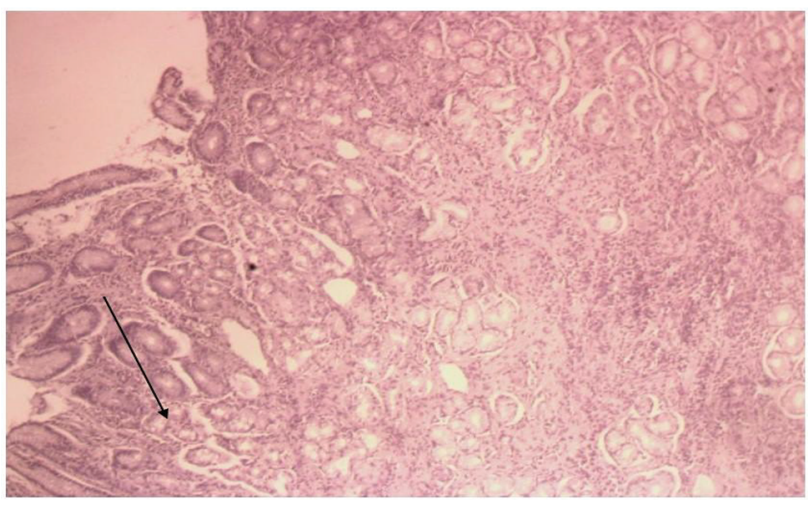

Figure 4 Mild gastric chronic inflammation (posttreatment result).

events $(\mathrm{RR}=0.971,95 \% \mathrm{CI}=0.46-2.04, P=0.937)$. Other adverse events (diarrhea, melena, and hematemesis) were not reported in both groups. Additionally, none of the patients experienced a major adverse event including renal damage, liver damage, and serum lipid profile abnormalities during therapy, as shown in Table 2.

No deaths occurred during treatment or 4 weeks of follow-up. One patient (receiving triple therapy and placebo) died shortly after the end of treatment and follow-up due to pneumonia. The death of the patient was not related to the study treatment as reported by the treating physician.

\section{Discussion}

Despite advances in understanding the pathophysiological mechanisms of PUD, clinical trials testing disease-specific therapeutics in combination with conventional triple therapy for PUD are scarce. ${ }^{18-20}$ This analysis of efficacy and adverse events in this double-blind randomized trial for adult patients with PUD clearly shows that coadministration of Syferol-IHP and conventional triple therapy of rabeprazole, amoxicillin, and clarithromycin significantly reduced the severity of symptoms of PUD and of patient-reported symptoms, without any significant adverse events compared with triple therapy and placebo. However, rapid recovery was seen, with the reduction in all incidences of epigastric pain at least 4 weeks after randomization, and without significant differences in adverse events. Therefore, significant differences were recorded for the disappearance of epigastric pain $(\mathrm{NNT}=3.7)$ and healing of the ulcer and rate of gastritis $(\mathrm{NNT}=3.6)$ and gastric ulcer $(\mathrm{NNT}=1.7)$ but not duodenitis $(\mathrm{NNT}=4.0)$ or duodenal ulcer $(\mathrm{NNT}=3.0)$ in the Syferol-IHP in combination with triple therapy group compared with the triple therapy and placebo groups. 
The primary endpoint of our study, healing of gastric ulcer confirmed by endoscopy 4 weeks after the commencement of treatment, was significantly better in patients receiving Syferol-IHP than in patients receiving placebo, although the healing of duodenal ulcer did not show significant difference between the two groups. It is important to note that the overall effects of Syferol-IHP appear to have high predilection to gastric mucosa than duodenal mucosa. The H. pylori eradication at the follow-up endoscopy-directed biopsy was $100 \%$ with Syferol-IHP population and $50 \%$ with placebo population $(P=0.066)$. These findings were comparable to previous study by Delchier et a ${ }^{19}$ in multi-European countries involving quadruple therapy. In a comparable prospective non-randomized study involving quadruple therapy in Italy, $95 \%$ of $H$. pylori-positive patients were successfully treated, although our present study was a randomized control trial in design but with lower sample size. ${ }^{5}$ Previous studies have indicated the positive effect of VCO on ulcer healing in animal models. ${ }^{9}{ }^{12}$ Findings of study by Anosike and $\mathrm{Obidoa}^{9}$ and Nneli and Woyike ${ }^{12}$ indicated that VCO plays an important cytoprotective role in gastric and duodenal ulcer diseases. Previous studies have also revealed the synergistic effects of $O$. sanctum oil, which is basil oil used as flavoring liquor for VCO. Akin to VCO, O. sanctum oil has been reported to have antibacterial and antiulcerogenic properties. ${ }^{13-15}$

Our study has also revealed that in all the study populations, the prevalence of gastric ulcer was $20 \%$, which was equal to the prevalence of duodenal ulcer of $20 \%$. These findings are in great contrast to results of previous epidemiological studies conducted in Europe, which showed a prevalence of $4.1 \%$ (gastric ulcer $2 \%$ and duodenal ulcer $2.1 \%$ ) $^{21}$ to $6.2 \%$ (gastric ulcer $2.3 \%$ and duodenal ulcers $3.9 \%$ ), ${ }^{22}$ with the prevalence of gastric ulcers in all these studies being less than duodenal ulcer or higher than duodenal ulcer. Also, in a systematic review by $\mathrm{Li}$ et $\mathrm{al},{ }^{23}$ the prevalence of gastric ulcer and duodenal ulcer in China was $1.6 \%$ and $13.3 \%$, respectively. The difference could be explained based on the fact that while the previous studies were done in the general population, ours were performed in patients with dyspeptic symptoms referred for endoscopy. This explanation is plausible because in one recent study involving only women with PUD diagnosed endoscopically, the prevalence of gastric ulcer was $55.5 \%$ and that of duodenal ulcer was $45.5 \%{ }^{24}$

The prevalence of $H$. pylori in patients with peptic ulcer in Nigeria would be expected to approach $100 \%$. However, in our case, more than $50 \%$ of the patients were negative for the infection. In fact, a previous Nigeria study by Jemilohun et $\mathrm{a}^{25}$ that relied on biopsy-based method (similar to our index study) revealed that the diagnosis of $H$. pylori was made in only $64 \%$ of patients. Another study by Olokoba et $\mathrm{al}^{26}$ revealed a prevalence rate of $80.0 \%$ using a biopsy-based method. The difference between our findings and those of previous studies could be that women with normal findings at endoscopy were excluded from the study. This reason could be reliable because a previous study by Jemilohun et al showed that $72.2 \%$ of the patients who had normal endoscopic findings were $H$. pylori positive.

In the present study, in terms of the epigastric pain, there was a significant difference between the Syferol-IHP and the placebo groups and the NNT was 3.7. This means that about four patients are needed to be treated with Syferol-IHP and conventional triple therapy for one of them to benefit compared with a conventional triple therapy alone in a clinical trial. Similar reduction outcomes were reported in cases of gastritis and duodenitis but that of duodenitis did not reach significant levels between the two treatment arms. The statistical significant difference seen in both groups with respect to the disappearance of epigastric pain and the healing of ulcer and rate of gastritis could be due to synergistic effect of the antibacterial and antiulcer properties of Syferol-IHP and triple regimen combination. Therefore, this paves way for a proposal of making Syferol-IHP an important addition to the regular triple therapy regimen in patients with gastritis and gastric ulcerations.

In view of these findings, a treatment concept that combines Syferol-IHP and triple therapy, as evaluated in the present study, appears to be associated with a superior clinical outcome, although a number of factors have to be taken into account, which may have an impact on patient clinical outcome, such as geographical regions, previously failed triple therapy, resistance issues, and different diagnostic tool opportunities. For instance, triple therapy containing clarithromycin but not metronidazole appears to be the most prescribed therapy in the study population and there could be high occurrence of clarithromycin-resistant $H$. pylori strains, which could justify the quadruple therapy ${ }^{20} \mathrm{Also}$, considering the apparently noncompliance rate of PUD therapy in the study population, we decided to use Pylorest (three-in-one tablet) to avoid any risk of failure of compliance to therapy during the course of the study. ${ }^{20}$

Again, none of the patients experienced a major adverse event including death, renal or liver damage, or serum lipid profile abnormalities during therapy. ${ }^{27}$ These abnormal changes were not observed in the present study, indicating that the study products appear to be safe.

Our findings have some strengths. First, this is the first randomized controlled study confirming that the use of this 
new quadruple therapy involving Syferol-IHP and triple therapy was effective. Therefore, Syferol-IHP is a combined natural product therapy, which suggests synergism in effective management of the PUD. ${ }^{16,17}$ Moreover, we found that this therapeutic quadruple regimen is always effective, both as ulcer therapy and nonulcer (gastritis, duodenitis) therapy; in both cases, the eradication rate was $>95 \%$.

The second strength of our study is the safety of the treatment regimen. Adverse events were reported in $8.3 \%$ of the enrolled patients and none of the patients had to discontinue the treatment due to adverse effects. These findings were lower than findings of Delchier et al, ${ }^{19}$ which reported mild adverse effects in $67 \%$ of patients. However, cases of nausea, vomiting, and dizziness occurred in our population, but none led to the discontinuation of treatment.

As a limitation of our study, we did not have a control group without any triple combination therapy because it was considered unethical withholding conventional therapy in patients with PUD without any prior randomized trial comparing the use of Syferol-IHP for the treatment of PUD. We therefore compared patients receiving SyferolIHP and triple therapy and patients receiving placebo and triple therapy. The results of the present study are to be considered as preliminary or pilot, to be confirmed in larger patient cohorts. Some patients may have been over treated because all patients with the diagnosis of PUD at endoscopy received $H$. pylori treatment, even though some of them were confirmed to be $H$. pylori free at histology of the biopsied specimen. Thus, H. pylori status was an exploratory outcome. Another potential limitation is the nonuse of permutated block randomization pattern, which could not allow us to allocate even number of individuals from both trial arms since the study was stopped after completing the follow-up of 60 participants due to costs.

\section{Conclusion}

The results of this study may suggest that Syferol-IHP in combination with conventional triple therapy is more efficacious (produces high cure rates) than conventional triple therapy alone for improving symptoms and signs of PUD. Both treatment arms were equally safe and well tolerated.

\section{Acknowledgments}

The authors would like to thank the study sponsor (Bioresource Development Group, Nigeria) for providing the product (Syferol-IHP) and placebo for this study free of charge. Publication of these results should not be considered an endorsement of any product used in this study by the Nnamdi Azikiwe University or any of the organizations where the authors are affiliated. Funding for this study was provided by Bioresource Development Group, Nigeria. The sponsor of the study was not involved in the conduct, interpretation, or preparation of the final manuscript.

\section{Author contributions}

GUE, COE, HAO, and JII conceived and designed the study, secured funding for project, and assisted with data analysis and manuscript preparation. $\mathrm{CDE}, \mathrm{SNC}, \mathrm{EIO}$, and $\mathrm{MEO}$ provided medical and surgical oversight, subject screening, and subject recruitment and assisted with manuscript preparation. FBCO, OIE, CGU, and LIN-I carried out subject recruitment, data collection, coordination of the study, and compliance. GWN assisted with data analysis and helped prepare the manuscript. All authors contributed to data analysis, drafting or revising the article, gave final approval of the version to be published, and agree to be accountable for all aspects of the work.

\section{Disclosure}

The authors report no conflicts of interest in this work.

\section{References}

1. Lanas A, Chan FK. Peptic ulcer disease. Lancet. 2017 (16):32404-32407.

2. Tsukanov VV, Kasparov EV, Tonkikh JL, et al. Peptic ulcer disease and Helicobacter pylori infection in different siberian ethnicities. Helicobacter. 2017;22(1):e12322.

3. Dongo AE, Uhunmwagho O, Kesieme EB, Eluehike SU, Alufohai EF. A Five-year review of perforated peptic ulcer disease in Irrua, Nigeria. Int Sch Res Notices. 2017;2017:eCollection 2017:1-6.

4. Sung JJ, Kuipers EJ, El-Serag HB. Systematic review: the global incidence and prevalence of peptic ulcer disease. Aliment Pharmacol Ther 2009;29(9):938-946.

5. Tursi A, di Mario F, Franceschi M, et al. New bismuth-containing quadruple therapy in patients infected with Helicobacter pylori: a first Italian experience in clinical practice. Helicobacter. 2017;22(3): e12371.

6. Wang B, Lv ZF, Wang YH, et al. Standard triple therapy for Helicobacter pylori infection in China: a meta-analysis. World J Gastroenterol. 2014;20(40):14973-14985.

7. Ford AC, Gurusamy KS, Delaney B, Forman D, Moayyedi P. Eradication therapy for peptic ulcer disease in Helicobacter pylori-positive people. Cochrane Database Syst Rev. 2016;4:CD003840.

8. Yang YJ, Bang CS, Shin SP, et al. Clinical characteristics of peptic ulcer perforation in Korea. World J Gastroenterol. 2017;23(14):2566-2574.

9. Anosike CA, Obidoa O. Anti-inflammatory and anti-ulcerogenic effect of ethanol extract of coconut (cocos nucifera) on experimental rats. Afr J Food Agric Nutr Dev. 2010;10(10):4286-4300.

10. Fife B. The Healing Miracles of Coconut Oil. 3rd ed. Colorado Springs: Piccadilly Books Ltd, Healthwise Publications; 2000:1-46.

11. Derle DV, Gujar KN, Sagar BSH. Adverse effects associated with the use of nonsteroidal antiinflammatory drugs: an overview. Indian J Pharm Sci. 2006;68(4):409-414. 
12. Nneli RO, Woyike OA. Antiulcerogenic effects of coconut (Cocos nucifera) extract in rats. Phytother Res. 2008;22(7):970-972.

13. Stomach Ulcer and Virgin Cold Pressed Coconut Oil - Health - Nairaland. Available from: http://www.nairaland.com/2325132/stomachulcer-virgin-cold-pressed. Accessed August 3, 2017.

14. Pinna S. Virgin Coconut Oil and Stomach Acid; 2016. Available from: http://drpinna.com/virgin-coconut-oil-and-stomach-acid-16443. Accessed August 3, 2017.

15. Singh S, Majumdar DK. Evaluation of the gastric antiulcer activity of fixed oil of Ocimum sanctum (Holy Basil). J Ethnopharmacol. 1999;65(1):13-19.

16. Phillipson JD. Phytochemistry and medicinal plants. Phytochemistry. 2001;56(3):237-243.

17. Gilbert B, Alves L. Synergy in plant medicines. Curr Med Chem. 2003;10(1):13-20.

18. Gómez Rodríguez BJ, Castro Laria L, Argüelles Arias F, et al. A real life study of Helicobacter pylori eradication with bismuth quadruple therapy in naïve and previously treated patients. Rev Esp Enferm Dig. 2017;109(8):552-558.

19. Delchier JC, Malfertheiner P, Thieroff-Ekerdt R. Use of a combination formulation of bismuth, metronidazole and tetracycline with omeprazole as a rescue therapy for eradication of Helicobacter pylori. Aliment Pharmacol Ther. 2014;40(2):171-177.
20. Olokoba AB, Obateru OA, Bojuwoye MO. Helicobacter pylori eradication therapy: a review of current trends. Niger Med J. 2013;54(1):1-4.

21. Aro P, Storskrubb T, Ronkainen J, et al. Peptic ulcer disease in a general adult population: the Kalixanda study: a random population-based study. Am J Epidemiol. 2006;163(11):1025-1034.

22. Zagari RM, Law GR, Fuccio L, Pozzato P, Forman D, Bazzoli F. Dyspeptic symptoms and endoscopic findings in the community: the Loiano-Monghidoro study. Am J Gastroenterol. 2010;105(3):565-571.

23. Li Z, Zou D, Ma X, et al. Epidemiology of peptic ulcer disease: endoscopic results of the systematic investigation of gastrointestinal disease in China. Am J Gastroenterol. 2010;105(12):2570-2577.

24. Yazdanpanah K, Parhizkar B, Sheikhesmaeili F, Roshani M, Nayebi M, Gharibi F. Efficacy of zinc sulfate in peptic ulcer disease: a randomized double-blind clinical trial study. J Clin Diagn Res. 2016;10(8):OC11-OC15.

25. Jemilohun AC, Otegbayo JA, Ola SO, Oluwasola OA, Akere A. Prevalence of Helicobacter pylori among Nigerian patients with dyspepsia in Ibadan. Pan Afr Med J. 2010;6:18.

26. Olokoba AB, Gashau W, Bwala S, Adamu A, Salawu FK. Helicobacter pylori infection in Nigerians with dyspepsia. Ghana Med J. 2013;47(2):79-81.

27. Nyblom H, Björnsson E, Simrén M, Aldenborg F, Almer S, Olsson R. The AST/ALT ratio as an indicator of cirrhosis in patients with PBC. Liver Int. 2006;26(7):840-845.
Clinical and Experimental Gastroenterology

\section{Publish your work in this journal}

Clinical and Experimental Gastroenterology is an international, peerreviewed, open access, online journal publishing original research, reports, editorials, reviews and commentaries on all aspects of gastroenterology in the clinic and laboratory. This journal is included on PubMed. The manuscript management system is completely online

\section{Dovepress}

and includes a very quick and fair peer-review system, which is all easy to use. Visit http://www.dovepress.com/testimonials.php to read real quotes from published authors. 